\title{
CIÊNCIA DA LÓGICA. LIVRO III-A LÓGICA SUBJETIVA. SEÇÃO 3-A IDÉIA. \\ CAPÍTULO 1-A VIDA ${ }^{1}$
}

\section{Georg Wilhelm Friedrich Hegel}

Tradução: Marcelo Gross VILLANOVA²

A idéia da vida concerne um objeto tão concreto e, se se quiser, tão real, que ela parece ter ultrapassado o âmbito da lógica, tal como é comumente concebida. Certamente, se a lógica não contivesse nada além de formas de pensamento, vazias e mortas, então não poderia ela tratar de nenhum conteúdo tal como a idéia ou a vida. Se, porém, a verdade absoluta é objeto da lógica e a verdade como tal consiste essencialmente em conhecer, então o conhecer teria que, pelo menos, ser tratado por ela. À assim chamada lógica pura, segue-se, geralmente, uma lógica aplicada - uma lógica que se ocupa do conhecer concreto, que não alude à magnitude da psicologia e da antropologia, que se considera necessário entrelaçar na lógica. O lado antropológico e psicológico do conhecer concerne, porém, seu fenômeno (ErScheinung), em cujo conceito, para si mesmo, não consiste ainda em ter por objeto uma objetividade igual a si mesmo, isto é, ter a si mesmo como objeto. A parte da lógica que trata desse conhecer concreto não pertence à lógica aplicada como tal; de outro modo, toda ciência teria que ser incluída na lógica, pois cada ciência, na medida em que consiste em ser uma lógica aplicada, compreende seu objeto nas formas do pensamento e do conceito. O conceito subjetivo tem pressuposições que se apresentam sob formas psicológicas, antropológicas e outras. À lógica, porém, pertencem apenas pressuposições do conceito puro na medida em que têm a forma do pensa-

1 HEGEL, G.W.F. Kapitel 1: Das Leben. Abschnitt 3: Die Idee. Buch III: Wissenshaft de subjectiven Logik oder die Lehre vom Begriff. Wissenschaft der Logik. Hamburgo: Felix Meiner, 1969, v.2, p.413-29.

2 Doutorando no Programa de Pós-Graduação em Filosofia da Universidade de São Paulo-Usp sob orientação de Maria das Graças de Souza. Tradução recebida em ago/06 a aprovado para publicação em nov/06. 
mento puro de essencialidades abstratas, as determinações do ser e da essência (des Seins und Wesens). Do mesmo modo, no que tange ao conhecer, a apreensão em si mesma do conceito, não se trata na lógica de outras figurações (Gestalten) da sua pressuposição; mas somente com aquela que é, ela mesma, idéia, que é necessário ser tratada na lógica. Agora essa pressuposição é a idéia imediata; pois, sendo o conhecer do conceito (na medida em que existe senão como subjetivo em relação a um objetivo), o conceito se refere à idéia como pressuposta ou imediata. A idéia imediata é, contudo, a vida.

Neste ponto, a necessidade de se considerar a idéia da vida na lógica se fundaria sobre a necessidade, reconhecida, também, por outro lado, de tratar aqui do conceito concreto do conhecer (Erkennen). Esta idéia, porém, foi introduzida pela própria necessidade do conceito; a idéia, o verdadeiro em si e para si (das an und für sich Wahre), é essencialmente objeto da lógica; já que ela é considerada, primeiramente, na sua imediatez, assim ela é concebida e conhecida ( $z u$ erkennen) nesta determinação, no qual ela é vida, para que sua consideração não seja algo vazio e carente de determinação. Pode ser apenas aproximadamente considerado em que medida se diferencia a perspectiva lógica da vida de outras perspectivas científicas sobre ela; este não é o lugar, entretanto, para considerar como a vida é tratada pelas ciências não-filosóficas, senão somente como a vida lógica, enquanto idéia pura, diferencia-se da vida natural, que se considera na filosofia natural, e da vida, enquanto está em vinculação com o espírito. A primeira, como vida da natureza, é vida, como projeção lançada para fora na exterioridade do subsistir (Äusserlichkeit des Bestehens), tem sua condição na natureza orgânica, e como os momentos da idéia são uma multiplicidade de formações reais. A vida na idéia não tem essas pressuposições (Voraussetzungen), que são como formas da efetividade (Wirklichkeit), sua pressuposição é o conceito, tal como foi considerado, de um lado como subjetivo, de outro, como objetivo. Na natureza, a vida aparece como o mais alto nível, um nível de cuja exterioridade é, com isto, alcançada, indo-se para dentro de si (in sich gegangen ist) e se suspendendo na subjetividade. Na lógica, é o simples ser-dentro-de-si (Insichsein), que atingiu, na idéia da vida, a exterioridade que em verdade lhe corresponde. O conceito, que antes se apresentava em cena como subjetivo, é a alma da vida mesma; é o impulso que media sua realidade através da sua objetividade. Dado que a natureza a partir da sua exterioridade, atinge essa idéia, transcende ela mesma; seu fim não está como seu início, senão como seu limite, de onde ela se suspende a si mesma. Da mesma maneira, na idéia da vida, os momentos da sua realidade não adquirem a forma de efetividade exterior (äusserlicher Wirklichkeit), senão que permanecem incluídos na forma do conceito. 
No espírito, porém, a vida aparece em parte como oposta ao espírito mesmo e em parte como posta juntamente com ele, e essa unidade, por sua vez, como pura descendência gerada pelo espírito. Aqui, a vida é mesmo tomada, em geral, em seu sentido próprio, como vida natural, pois, o que se chama a vida do espírito como espírito, é sua peculiaridade, que se contrapõe a simples vida; assim como se fala também da natureza do espírito, apesar do espírito não ser algo natural e, muito mais, ser algo oposto à natureza. A vida é como tal, já um meio/instrumento (Mittel) para o espírito, assim, ele se contrapõe a si mesmo; já o espírito é um indivíduo vivo (lebendiges Individuum), e a vida, seu corpo; já esta unidade [de espírito] com sua corporalidade é gerada do espírito mesmo para formar o ideal. Nenhuma dessas relações com o espírito diz respeito à vida lógica e a vida não é considerada aqui nem como meio/instrumento de um espírito nem como seu corpo vivo e nem tampouco como momento do ideal e da beleza. Em ambos os casos, como vida natural e como em relação com o espírito, a vida tem uma determinação da sua exterioridade, no primeiro caso, por meio das suas pressuposições, que são outras figurações (Gestaltungen) da natureza, no segundo caso, através dos fins e da atividade do espírito. A idéia de vida por si está livre de cada objetividade pressuposta e que condiciona, bem como da relação com esta subjetividade.

A vida, agora considerada com mais proximidade na sua idéia, é, em si e para si, absoluta universalidade; a objetividade que tem em si, está permeada completamente por seu conceito, tendo somente o conceito como substância. O que se distingue como parte, ou que qualquer outra reflexão externa, tem todo o conceito em si mesmo; esse conceito é aqui a alma (Seele) onipresente, que perdura como simples relação consigo mesmo e como um todo único na multiplicidade, que pertence (zukommt) ao ser objetivo. Essa multiplicidade tem, como objetividade extrínseca a si mesmo, uma subsistência indiferente, que no espaço e no tempo (se estes puderem ser aqui mencionados), é uma recíproca externalidade e de todo diversa e autônoma. Na vida, contudo, a exterioridade se encontra ao mesmo tempo presente como simples determinação do seu conceito; assim, a alma está onipresentemente difundida na multiplicidade e, permanece, ao mesmo tempo, absolutamente o simples ser-uno (Einssein) do conceito concreto consigo mesmo. - O pensamento que se apega às determinações das relações de reflexão (Reflexionverhältnisse) e do conceito formal, quando chega a considerar a vida, a unidade do seu conceito na exterioridade da objetividade, na absoluta multiplicidade da matéria atomística, não encontra, sem exceção, serventia todas as suas reflexões; a onipresença do simples na exterioridade múltipla é, para a reflexão, uma absoluta contradição, e, como a reflexão, tem de ao mesmo tempo apreender essa onipresença da sua percepção da vida e, por conseguinte, admitir a efetividade (Wirklichkeit) des- 
ta idéia, com isto, um mistério incompreensível, porque ela, a reflexão, não alcança o conceito, não compreende o conceito enquanto substância da vida. A vida simples não é, todavia, apenas onipresente, mas sim, ela é absolutamente o subsistir (das Bestehen) e a substância imanente (immanente Substanz) da sua objetividade, como, porém, substância subjetiva, é impulso e, precisamente, um impulso específico da diferença particular, e, do mesmo modo, essencialmente o único e universal impulso do específico, que reconduz esta sua particularização a unidade e nela se mantém. É somente como esta unidade negativa da sua objetividade e particularização que a vida se auto-referencia e existe por si mesma, uma alma. Com isto, é essencialmente um indivíduo, que se refere a objetividade como a um outro, como a uma natureza carente de vida (unlebendige Natur).Conseqüentemente, o juízo originário da vida consiste .em que ela se separa, como sujeito individual em contraposição ao objetivo, e, ao constituir-se como a unidade negativa do conceito, forma a pressuposição (Vouraussetzung) de uma objetividade imediata.

Portanto, a vida tem que ser considerada em primeiro lugar enquanto indivíduo vivo, que é por si a totalidade subjetiva e está pressuposto como indiferente frente a uma objetividade que se confronta com ele também indiferente a ela.

Em segundo lugar, é o processo vital que consiste em suspender (aufheben) sua pressuposição, posta como negativa a objetividade que está indiferente frente a ele e efetivando como seu poder e unidade negativa. Com isto, se converte no universal, que é a unidade de si mesmo e do seu outro. A vida é, por conseguinte, em terceiro lugar, o processo do gênero, que consiste em suspender (aufheben) sua individualização e referi-se ao seu ser-aí objetivo (objetives Dasein) como a si mesmo. Esse processo é, com isto, um retorno ao seu conceito, por um lado, e a repetição da sua primeira divisão (Diremtion), o vir-a-ser de uma nova individualidade e a morte da primeira individualidade imediata;por outro lado, contudo, o conceito de vida que retornou em si é o vir-a-ser do conceito que se relaciona consigo mesmo, que existe por si como universal e livre, isto é, é a transição ao conhecer.

\section{III/3-1.A. O indivíduo vivo}

1. O conceito de vida ou a vida universal é a idéia imediata, o conceito, cuja objetividade lhe é apropriada; sua objetividade é, todavia, somente apropriada, na medida em que o conceito é a unidade negativa desta exterioridade, quer dizer, pondo-se como apropriada. A relação infinita do conceito por si mesmo (auf sich selbst) é, como negatividade, o auto-determinar-se, a divisão (Diremtion) [da sua individualidade subjetiva/dele] dentro 
de si (in sich), como individualidade subjetiva, e dentro de si (in sich) como universalidade indiferente. A idéia da vida na sua imediatez (Unmittelbarkeit) é primeiro somente a alma universal criadora (schöpferische allgemeine Seele). Por causa desta imediatez, a primeira relação negativa da idéia dentro de si mesma (in sich selbst) é a auto-determinação dela como conceito, - é o pôr-se em si que somente como retorno a si é ser-para-si (Fürsich-sein), o pressupor criador. Por meio deste autodeterminar-se, a vida universal tornar-se um particular (Besonderes), dividindo-se, com isto, em dois extremos do juízo, que imediatamente torna-se silogismo.

As determinações da oposição são as determinações universais do conceito, pois é o conceito aquele ao qual pertence (zukommt) a divisão; mas o estofo (Erfüllung) destas determinações é a idéia. Um extremo é a unidade do conceito e da realidade (Realität), unidade que é idéia, como idéia imediata, que antes já havia se apresentado como objetividade. Mas aqui como outra determinação. Lá era unidade do conceito e da realidade, na medida em que o conceito havia se transformado e somente se perdido nela; o conceito não se encontra frente a ela, ou [em outras palavras] porque o conceito é para a realidade somente interno, ele é somente uma reflexão externa sua. Aquela objetividade é, assim, o imediato mesmo na sua forma imediata. Aqui, ao contrário, ela procede apenas do conceito, de modo que sua essência consiste em ser posto que ela está como negativa. - Ela tem que ser considerada como o lado da universalidade do conceito, com isto, como universalidade abstrata, essencialmente somente inerente no sujeito e na forma do ser imediato, posto para si, indiferente frente ao sujeito. Com isto, a totalidade do conceito que pertence à objetividade é como que somente tomada em empréstimo; a última autonomia (Selbständigkeit) que há frente ao sujeito, consiste naquele ser, que, segundo sua verdade, é somente aquele momento do conceito, que, como se pressupondo na primeira determinidade (Bestimmtheit) de um pôr-se existente em si, que ainda não existe como pôr-se, como unidade refletida dentro de si. Assim, ao sair da idéia, a objetividade autônoma é um ser imediato somente como predicado do juízo da autodeterminação (Selbstbestimmung) do conceito, - um ser que por certo é diferente do sujeito que, contudo, ao mesmo tempo está posto essencialmente como momento do conceito

Com respeito ao conteúdo, a objetividade é a totalidade do conceito, que, todavia, foi confrontada à subjetividade ou unidade negativa daquele, do qual constitui a verdadeira centralidade, quer dizer, sua livre unidade consigo mesma. Este sujeito é a idéia na forma da individualidade como simples ainda que negativa identidade consigo, o indivíduo vivo.

Este é, primeiramente, vida como alma, como o conceito de si mesmo, que dentro de si (in sich) está totalmente determinado, como princípio que inaugura e que se move a si mesmo. O conceito contém na sua simplicida- 
de a exterioridade determinada como simples momento incluído em si. Além disso, contudo, esta alma é, na sua imediatez (Unmittelbarkeit), imediata-extrínseca e possui um ser objetivo nela mesma (an ihr selbst), - a realidade submetida a fim, o meio imediato, em primeiro lugar, a objetividade como predicado do sujeito; mais adiante, todavia, ela é também o termo médio do silogismo (Mitte des Schlusses), a corporalidade da alma é aquela, por cujo meio ela se une com a objetividade exterior. - O ser vivo (das Lebendige) tem a corporalidade em primeira instância como realidade, que é imediatamente idêntica com o conceito; com isto, a alma tem esta corporalidade em geral da natureza.

Agora, como a objetividade é predicado do indivíduo e foi acolhida na unidade subjetiva, as determinações antecedentes do objeto, a relação mecânica e química não pertencem (zukommen) a ele, menos ainda as relações de reflexão abstratas do todo e das partes, e coisas semelhantes. Como exterioridade ela é capaz de tais relações; todavia, com isto ela não é um seraí vivo (lebendiges Dasein); quando o ser vivo (das Lebendige) é considerado com um todo, que consiste em partes, como algo que sobre ele influenciam causas mecânicas ou químicas, como produto mecânico ou químico (seja considerado meramente como produto ou determinado também por um fim externo), então, o conceito lhe é extrínsico, [o ser vivo é] dado como morto. Posto que o conceito lhe é imanente, a finalidade do ser vivo (das Lebendige) é concebida como interna; o conceito é nele como determinado, diferente da sua exterioridade e, na sua distinção, penetra a exterioridade e permace idêntico, o conceito, consigo mesmo. Esta objetividade do ser vivo (Lebendigen) é organismo; a objetividade é o meio e o instrumento do fim, perfeito na sua correspondência, já que o conceito constitui sua substância (Substanz); precisamente por isso o fim realizado em que o fim subjetivo é, deste modo, de imediato encadeado consigo mesmo. O organismo, em respeito a sua externalidade, é um múltiplo, que não se compõe de partes, mas sim de membros, que, como tais, a) subsistem (bestehen) somente na sua individualidade; eles são separáveis, deste modo, são externos e podem ser considerados nesta externalidade; deste modo, todavia, separá-los, retrocedem (zurückehren) sob as relações mecânicas e químicas da objetividade comum. b) A externalidade deles é contrária à unidade negativa do indivíduo vivo; por conseguinte, esta é impulso (Trieb), o momento abstrato da determinação do conceito posto (zu setzen) como diferença real. Dado que esta diferença é imediata, o impulso (Trieb) é cada único momento específico a produzir-se e também a elevar sua particularidade a universalidade, a superar (aufheben) os outros momentos a ele, a produzir-se a custa deles, mas, do mesmo modo, a superar-se (aufheben) a si mesmo e fazer-se (sich machen zu) a si mesmo como meio para o outros. 
2. Este processo da individualidade viva está limitado a si mesmo e cai ainda inteiramente no interior dela. - No silogismo (Schlusse) da finalidade exterior considera-se antes sua primeira premissa (ou seja, que o fim imediato se refere à objetividade e se faz a si mesmo como meio), no sentido de que na premissa o fim, na verdade, permanece igual a si mesma e retornou dentro de si, contudo, a objetividade não se superou (aufgehoben) em si mesma (an sich selbst) ainda, por conseguinte, o fim dentro dela [premissa] não é em si e para si (an und für sich) e isto virá somente na conclusão. O processo do ser vivo consigo mesmo é a mesma premissa, todavia, ela é ao mesmo tempo conclusão, e, nisso, a relação imediata do sujeito a objetividade, que se torna, através disso, meio e instrumento, é, ao mesmo tempo, como unidade negativa do conceito em si mesma (an sich selbst). O fim se realiza nesta sua externalidade, pelo fato de que nela está seu poder subjetivo (subjektive Macht) e é o processo em que mostra seu desenlace e o retorno a esta unidade negativa [do fim]. A inquietude e variabilidade do lado externo do ser vivo é a manifestação nele do conceito, que tem, como negatividade em si mesma, somente objetividade, contanto que seu subsistir indiferente se mostre superando-se (sich aufhebend). O conceito se produz também através do seu impulso (Trieb) de maneira tal, que o produto, em cuja essência é o conceito, é, ele mesmo, o agente produtor (das Produzierende), de maneira que o produto é somente como exterioridade, posta igualmente de modo negativo, ou seja, como o processo de produção.

3. A idéia acima considerada é, então, o conceito de sujeito vivo e de seu processo; as determinações que estão em relação entre elas são a unidade negativa do conceito, que se refere a si mesma e a objetividade, que é o meio do conceito, no qual, todavia, o conceito havia retornado dentro de si mesmo (in sich selbst). Mas como estes são momentos da idéia da vida no interior do seu conceito, não são momentos conceituais determinados do indivíduo vivo na sua realidade. A objetividade ou corporalidade dele é uma totalidade concreta; aqueles momentos são os lados, com os quais se constitui a vitalidade (Lebendigkeit). Contudo, a objetividade viva do indivíduo, como tal, desde que animada pelo conceito, e tendo o conceito por sua substância, também nela, possui para suas diferenças essenciais suas determinações do conceito, universalidade, particularidade e individualidade; por conseguinte, a figura (Gestalt), na qual estas determinações estão exteriormente distinguidas, está dividida ou cortada (insectum) [com base nesta diferença]

Com isto, ela [a vitalidade] é, em primeiro lugar, universalidade, o puro vibrar somente dentro de si mesma (in sich selbst) da vitalidade, a sensibilidade (Sensibilität). O conceito de universalidade, segundo resultou anteriormente, é a simples imediatez (Unmittelbarkeit), que é, contudo, somen- 
te absoluta negatividade dentro de si (in sich). Este conceito da absoluta diferença, posto que sua negatividade se dissolve na simplicidade e é igual a si mesma, foi levada para a intuição (Anschauung) na sensibilidade. Ela [sensibilidade] é o ser-dentro-de-si (Insichsein), não como simplicidade abstrata, mas sim como receptividade infinita determinada, que, em sua determinação, não se torna um múltiplo e um exterior, mas sim que está refletida pura e simplesmente em si. A determinidade (Bestimmtheit), nesta universalidade, está presente como simples princípio; a determinidade externa singular, a chamada impressão, retorna da sua determinação externa e múltipla a esta simplicidade da percepção de si (Selbstgefühl). A sensibilidade pode, assim, ser considerada como o ser-aí (Dasein) da alma existente dentro-de-si, pois que toda exterioridade acolhe-se a si mesma, a mesma, contudo, reduz-se à completa simplicidade da universalidade igual a si mesma.

A segunda determinação (Bestimmung) do conceito é a particularidade (Besonderheit), o momento das diferenças postas; a abertura da negatividade, que está cerrada (eingeschlossen) na simples percepção de si, ou é um ideal, ainda que não real determinidade (Bestimmtheit), - a irritabilidade. Por conta da abstração da sua negatividade, o sentimento é um impulso; determina-se. A autodeterminação do ser vivo é seu julgamento ou sua auto-limitação (Verendlichung), por cujo meio se refere a realidade exterior como pressuposta e está em ação recíproca (Wechselwirkung) com ela. Segundo sua particularidade é, de um lado, uma espécie ao lado de outras espécies de seres vivos; a reflexão formal em si desta heterogeneidade indiferente é o gênero (Gattung) formal e sua sistematização; contudo, a reflexão individual consiste em que a particularidade, a negatividade da sua determinidade (Bestimmtheit), como que uma direção para o exterior, é a negatividade do conceito, que se refere a si mesma.

De acordo com essa terceira determinação, o ser vivo existe como indivíduo. Mais precisamente, esta reflexão-dentro-de-si (Reflexion-in-sich) se determina de modo tal que o ser vivo é, na irritabilidade, exterioridade de si frente a si mesmo (Äusserlichkeit seiner gegen sich selbst), frente a objetividade, que tem imediatamente em si, como seu meio e instrumento, e que pode ser determinada de modo extrínseco. A reflexão-dentro-de-si (Reflexion-in-sich) suspende (aufhebt) esta imediatez, por um lado, como reflexão teórica, quer dizer, à medida em que a negatividade está presente como momento simples da sensibilidade, que foi considerado recentemente e que constitui o sentimento - por outro lado, como reflexão real, - no qual a unidade do conceito se põe na sua objetividade exterior como unidade negativa: a reprodução. - Os primeiros dois momentos, a sensibilidade e a irritabilidade, são determinações (Bestimmungen) abstratas; a vida é, na reprodução, algo concreto e é vitalidade; tem em si, na sua verdade, primeiro também sentimento (Gefühl) e força de resistência (Widerstandkraft). A re- 
produção é a negatividade como simples momento da sensibilidade, e a irritabilidade é apenas força de resistência viva, de modo que a relação com o exterior é reprodução e identidade individual consigo mesma. Cada um dos momentos particulares é essencialmente a totalidade de todos; sua diferença constitui a determinidade ideal da forma (ideelle Formbestimmtheit), que está posta na reprodução como totalidade concreta do todo. O todo é, assim, por um lado, como um terceiro, quer dizer, como totalidade real, oposto àquelas totalidades determinadas, por outro, é a essencialidade (Wesenheit) daquelas existentes em si, ao mesmo tempo onde estão concentradas como momentos e têm seu sujeito e seu subsistir.

Com a reprodução põe-se, como momento da singularidade (Einzelheit), o ser vivo (das Lebendige) como individualidade efetiva (wirkliche Individualität), um ser-para-si que se refere a si mesmo (ein sich auf sich beziehendes Fürsichsein), contudo, é, ao mesmo tempo, relação real ao exterior, a reflexão da particularidade ou irritabilidade frente a um outro, frente ao mundo objetivo. O processo da vida fechado no interior do indivíduo passa na relação à objetividade pressuposta como tal dele, faz o indivíduo em se pondo como totalidade subjetiva, também o momento da sua determinidade (Bestimmtheit) como relação à exterioridade, torna-se a totalidade.

\section{III/3-1.B. O processo vital}

O indivíduo vivo, ao (con)figurar-se (sich gestaltet) dentro de si (in sich selbst), tensiona contra seu pressupor original e se coloca como sujeito existente (seiendes Subjekt) em si e para si (an und für sich) frente ao mundo objetivo pressuposto. O sujeito é seu próprio fim (Selbstzweck), o conceito, que tem seu meio e sua realidade subjetiva na objetividade a ele submetida. Com isto, está constituído como a idéia existente em si e para si (an und für sich seiende Idee) e como a autonomia essencial (das wesentliche Selbständige), frente ao qual o mundo externo pressuposto tem somente um valor negativo e heterônomo (Unselbständigen). O ser vivo tem, na sua percepção de si (Selbstgefühl) esta certeza da nulidade (Nichtigkeit), existente em si, do ser-outro com que se defronta (gegenüberstehenden Andersseins). Seu impulso é a necessidade de suspender (aufzuheben) o seroutro e dar-se a verdade daquela certeza. O indivíduo é, como sujeito, primeiramente conceito da idéia de vida; seu processo subjetivo dentro de si (in sich), em que ele se nutre (zehrt) de si mesmo, e a objetividade imediata, que ele põe como meio natural conforme seu conceito, é mediado pelo processo, que se refere à exterioridade completamente posta, a totalidade objetiva que está de modo indiferente junto a ele. 
Este processo começa com a necessidade, isto é, em primeiro lugar, com o momento em que o ser vivo (das Lebendige) se determina, e, com isto, põe-se como negado e, por meio disso, se refere a uma objetividade frente ao outro, a objetividade indiferente. Em segundo lugar, contudo, igualmente nesta perda (Verlust) de si não se está perdido, senão que se conserva nisso e permanece a identidade do conceito igual a si mesmo; por meio disso, é o impulso a pôr, para si e igual a si, aquele mundo, que para ele é outro a superá-lo e a objetivar-se a si mesmo. Através disso, sua autodeterminação (Selbstbestimmung) tem a forma da exterioridade objetiva, e [através disso], sendo ao mesmo tempo idêntico consigo mesmo, é a absoluta contradição (absolute Widerspruch). A (con)figuração imediata (unmittelbare Gestaltung) é a idéia no seu conceito simples, é a objetividade conforme o conceito; assim, é boa por natureza. Todavia, por quanto o momento negativo foi realizado na forma de particularidade objetiva, isto é, por quanto os momentos essenciais da sua unidade foram realizados cada um para si como totalidade, assim, o conceito é cindido/provocado (entzweit) na desigualdade absoluta dele consigo mesmo, e por quanto é, do mesmo modo, a identidade absoluta nesta cisão (Entzweiung), assim, o ser vivo é para si mesmo (für sich selbst) esta cisão (Entzweiung) e tem o sentimento desta contradição, que é a dor (Schmerz). Por conseguinte, a dor é a prerrogativa das naturezas vivas; porque elas são o conceito existente (existierende Begriff), elas são uma efetividade (Wirklichkeit) da força infinita, elas são, dentro de si, a negatividade delas mesmas, que elas preservam (erhalten) no seu ser-outro (Anderssein). - Quando se diz que a contradição não seria pensável, a contradição é, antes pelo contrário, existência efetiva na dor do ser vivo.

Esta divisão (Diremtion) do ser vivo dentro de si (in sich) é sentimento (Gefühl), enquanto que essa divisão é acolhida dentro da universalidade simples do conceito, dentro da sensibilidade. A partir da dor começa a necessidade e o impulso (Trieb), que constituem a passagem pela qual o indivíduo, tal como é por si negação para si (für sich), torna-se também como identidade para si - uma identidade, que é somente como negação daquela negação. - A identidade, que está no impulso como tal, é a certeza subjetiva de si mesmo, segundo o qual, ele [o ser vivo/es] se refere ao seu mundo exterior, que existe de modo indiferente, como a um fenômeno (Erscheinung), ou como uma efetividade em si carente de conceito (begrifflosen) e inessencial. Esta [Wirklichkeit] deve antes receber o conceito dentro de si através do sujeito, que é o fim imanente. A indiferença do mundo objetivo frente a determinidade (Bestimmtheit) e, com isto, frente ao fim, constitui sua capacidade exterior ao ser conforme o sujeito; sejam quaisquer especificações que o mundo tenha em si, sua determinilidade (Bestimmtbarkeit) mecânica, a ausência na liberdade do conceito imanente constitui sua im- 
potência para manter-se frente ao ser vivo. - Na medida em que o objeto, frente ao ser vivo, é, em primeiro lugar, como uma exterioridade indiferente, pode atuar sobre aquele [ser vivo] de modo mecânico; assim, contudo, não atua sobre um ser vivo; onde ele entra em relação com este, não atua como causa, mas sim, excita-o. Dado que o ser vivo é impulso, a externalidade não pode aproximar-se ou entrar nele exceto se já estiver em e para si nele; a ação sobre o sujeito consiste, por conseguinte, somente em que se encontre adequada a exterioridade que se apresenta; - [esta exterioridade] pode não corresponder a totalidade do sujeito, assim, tem de corresponder, pelo menos, a um lado particular nele, e essa possibilidade reside em que o sujeito é, na sua relação externa, um particular.

O sujeito, agora, na medida em que se refere, na sua necessidade de maneira exterior, ao exterior, e ao ser, com isso, ele mesmo [algo de] exterior ou instrumento, usa da violência sobre o objeto. Seu caráter particular, sua finitude em geral tomba (fällt in) no fenômeno determinado desta relação. O exterior nisso é o processo da objetividade em geral, mecanismo e quimismo. Mas este mesmo [processo] é interrompido imediatamente e a exterioridade transforma-se em interioridade. A finalidade externa, que se encontra, em primeiro lugar, produzida pela atividade do sujeito em objeto indiferente, é suspendido (aufgehoben), porque o objeto não é uma substância frente ao conceito, e, por conseguinte, o conceito não somente pode tornar-se na sua forma exterior, mas tem de se por como sua essência e como sua determinação (Bestimmung) imanente, penetrante, conforme sua identidade originária.

Com a captura do objeto, o processo mecânico se transforma, por conseguinte, dentro do [processo] interior, pelo qual, o indivíduo se apropria do objeto, de sorte que o despoja da sua natureza peculiar (Beschaffenheit), o reduz a seu meio e dá por substância sua própria subjetividade. Essa assimilação vem, assim, coincidir com o processo de reprodução do indivíduo considerada acima; neste processo, ele [o indivíduo], alimenta-se, em primeiro lugar, de si mesmo, em fazendo-se de sua própria objetividade seu objeto; o conflito mecânico e químico dos seus membros com as coisas exteriores é um momento objetivo dele. O mecânico e químico do processo é o começo da dissolução do ser vivo. Dado que a vida é a verdade destes processos, e, com isto, como ser vivo, a existência dessa verdade e poder destes mesmos [processos], ela os invade, penetra como sua universalidade e o produto deles fica totalmente determinado pela vida mesma. Esta transformação na individualidade viva constitui o retorno desta última dentro de si mesma (in sich selbst), de tal sorte que a produção, que, como tal, seria o passar a um outro, transforma-se em reprodução, no qual o ser vivo põe-se para si, idêntico consigo mesmo. 
A idéia imediata é também a identidade imediata do conceito e da realidade, como identidade que não existe para si; por meio do processo objetivo, o ser vivo se dá como sua percepção de si (Selbstgefühl); pois ele se põe como pelo que é em e para si, quer dizer, para ser idêntico consigo mesmo no seu ser-outro, posto como indiferente, a unidade negativa do negativo. Neste coincidir do indivíduo com sua objetividade, que, primeiramente, estava pressuposta como indiferente, o indivíduo havia se constituído como unidade real, de outro lado, suspendeu (aufgehoben) sua particularidade e elevou-se a universalidade. Sua particularidade consistia na divisão (Diremtion), pela qual a vida pôs como suas espécies a vida individual e a objetividade exterior a esta. Através do processo vital externo, ela se pôs como vida real, vida universal, como gênero.

\section{III/3-1.C. O gênero}

O indivíduo vivo, primeiramente separado do conceito universal da vida, é uma pressuposição, que ainda não é autenticada [pelo indivíduo vivo] por si mesma. Mediante o processo com o mundo pressuposto ao mesmo tempo, ele pôs-se a si mesmo - para si (für sich) como unidade negativa do seu ser-outro - como a base de si mesmo; [o indivíduo] é, assim, como a efetividade (Wirklichkeit) da idéia, de tal sorte que o indivíduo produz-se a partir da efetividade, como antes era somente do conceito, e com seu surgimento, quer era um pressupor, agora, torna-se sua produção.

A determinação ulterior, todavia, obtida através da suspensão da oposição (Gegensatz), é do ser gênero como identidade sua com seu anterior ser-outro indiferente. Esta idéia do indivíduo, por ser uma totalidade essencial, é essencialmente a particularidade dele mesmo. Esta sua divisão (Diremtion) é, segundo a totalidade da qual procede, a duplicação do indivíduo - um pressupor (Vorausetzen) de uma objetividade, que é idêntica com ele, e uma relação (Verhalten) do sujeito consigo mesmo como a um outro ser vivo.

Este universal é o terceiro nível, a verdade da vida, na medida em que ainda está confinada no interior da sua esfera. Este nível é o processo que se refere a si do indivíduo, onde a exterioridade é seu momento imanente; em segundo lugar, esta exterioridade é ela mesma, como totalidade viva, uma objetividade, que para o indivíduo é ele mesmo, uma objetividade, não como suspendida (aufgehobener), mas como subsistente (bestehender), o indivíduo tem a certeza de si mesmo.

Agora, porque a relação do gênero é a identidade da percepção de si (Selbstgefühl) individual, na qual é, ao mesmo tempo, outro indivíduo autônomo (selbständiges), a relação é a contradição; o ser vivo é, com isto, no- 
vamente, impulso (Trieb). - O gênero é, certamente, a consumação (Vollendung) da idéia de vida, entretanto, ele está, em primeiro lugar, ainda no interior da esfera da imediatez; esta universalidade é, por conseguinte, efetiva dentro de uma figura singular (in einzelner Gestalt), - o conceito, cuja realidade da forma tem a objetividade imediata. O indivíduo é em si, por conseguinte, na verdade, gênero, mas não é para si (für sich) gênero; o que é para ele, é somente, primeiro, um outro indivíduo vivo; o conceito diferente de si tem por objeto, com o qual é idêntico a si, não a si mesmo como conceito, mas um conceito que, como ser vivo, tem, ao mesmo tempo, objetividade externa para ele, uma forma que é, por conseguinte, imediatamente recíproca.

A identidade com o outro, a universalidade do indivíduo, é, com isto, apenas, primeiro, interna ou subjetiva; por conseguinte, o indivíduo experimenta a ânsia (Verlangen) de pô-la [a identidade ao outro] e de realizar-se como universal. Este impulso do gênero pode, contudo, somente realizar-se pela suspensão (Aufhebung) das individualidades singulares, que são ainda particulares uma contra a outra. Em primeiro lugar, na medida em que estas são tais que satisfazem em geral em si a tensão da sua ânsia e se dissolvem na sua universalidade de gênero, assim, sua identidade realizada é a unidade negativa do gênero que se reflete a si mesma a partir da cisão (Entzweiung). Ela é, nesta medida, a individualidade da vida mesma, não mais gerada do seu conceito, mas sim, da idéia efetiva (aus der wirklichen Idee). Em primeiro lugar, ela mesma é somente o conceito, que, não obstante, objetivou-se, é o conceito efetivo, - o germe (Keim) de um indivíduo vivo. Nele [germe] encontra-se presente para a percepção comum o que é um conceito, e que o conceito subjetivo tem efetividade exterior. Pois o germe do ser vivo é a condensação (Konkretion) completa da individualidade, no qual todos os seus diferentes lados, propriedades e diferenças articuladas estão contidas na sua total determinidade (Bestimmtheit) e a totalidade, primeiramente imaterial e subjetiva, não está desenvolvida, é simples e não-sensível; o germe é, assim, o ser vivo total na forma interior do conceito.

A reflexão dentro de si do gênero é, segundo este lado, aquele por cujo meio o gênero obtém efetividade (Wirklichkeit), o momento da unidade negativa e da individualidade encontra posta nela - a propagação das gerações vivas. A idéia de que, como vida, está ainda na forma da imediatez (Unmittelbarkeit), recai, nesta medida, na efetividade, e esta reflexão sua é somente a repetição e o processo infinito, no qual ela não sai da finitude da sua imediatez. Mas esse retorno no seu primeiro conceito tem também seu lado mais elevado, que a idéia não meramente percorre a mediação dos seus processos no interior da imediatez, mas sim, justamente com isto, suspendeu (aufgehoben) esta imediatez e, através disso, elevou-se em uma forma mais elevada do seu ser-aí. 
O processo do gênero, com efeito, no qual os indivíduos singulares suspendem sua existência indiferente e imediata, uns dos outros, e perecem nessa unidade negativa tem, além disso, pelo outro lado da sua produção, o gênero realizado, que foi posto idêntico com o conceito. - No processo do gênero perecem as singularidades isoladas das vidas individuais; a identidade negativa, na qual o gênero volta-se dentro de si (in sich), é, como o engendramento da individualidade (Erzeugung der Einzelheit), de um lado, e de outro, a suspensão dela mesma [singularidade], o gênero, com isto, harmoniza-se (zusammengehen) consigo mesmo, a universalidade da idéia no processo de tornar-se por si mesma. Na cópula morre a imediatez do indivíduo vivo; a morte desta vida é o nascer do espírito. A idéia, que como gênero está em si (an sich), está para si (für sich), ao suspender sua particularidade, que constitui as gerações vivas, e, com isto, deu a si uma realidade (Realität), que é, ela mesma, universalidade simples; assim é ela a idéia, que se relaciona consigo como idéia, o universal que tem a universalidade como sua determinidade (Bestimmtheit) - a idéia do conhecer.

\section{Glossário}

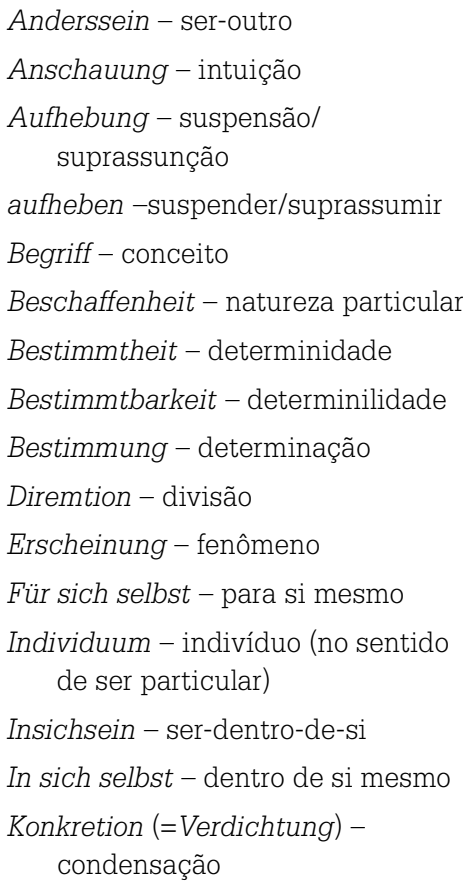

\author{
Lebendigkeit - vitalidade \\ lebendiges Dasein - o ser-aí vivo \\ Realität - realidade \\ Reflexion-in-sich - reflexão-dentro- \\ de-si \\ Schlusse - silogismo \\ Selbstbestimmung - \\ autodeterminação \\ selbständig - autônomo \\ Selbstgefühl - percepção de si \\ (geralmente traduzido por \\ "sentimento de si")
}

Sich gestalten - (con) figurar-se

Trieb - impulso

Unmittelbarkeit - imediatez

unselbständig - heterônomo

Voraussetzung - pressuposição

Vollendung - consumação

Wirklichkeit - efetividade 